\title{
A longitudinal examination of the relationship between cannabis use and cognitive function in mid-life adults
}

Running header: Cannabis use and cognition

Authors:

Rebecca McKetin ${ }^{1,2} \mathrm{PhD}$, rebecca.mcketin@curtin.edu.au

Praneeth Parasu² B.Engineering (Civil), u5513662@anu.edu.au

Nicolas Cherbuin ${ }^{2} \mathrm{PhD}$, nicolas.cherbuin@anu.edu.au

Ranmalee Eramudugolla ${ }^{2}, \mathrm{PhD}$, ranmalee.eramudugolla@anu.edu.au

Kaarin J. Anstey ${ }^{2} \mathrm{PhD}$, Kaarin.anstey@anu.edu.au

${ }^{1}$ National Drug Research Institute, Faculty of Health Science, Curtin University, Perth, Australia

${ }^{2}$ Centre for Research on Ageing, Health and Wellbeing, Australian National University, Canberra, Australia

Word count:

3,973 (excluding abstract, references, title page and tables), 3 Tables \& 1 Figure

Declaration of competing interests:

All authors declare that they have no conflicts of interest to disclose.

Key words: cannabis, cognitive function, substance-related disorders

Corresponding author and location of research:

A/Prof. Rebecca McKetin, National Drug Research Institute, Faculty of Health Science,

Curtin University, GPO Box 1987, Perth WA 6845

Ph. + 61892661602

Fax. +61 892661611

Email: rebecca.mcketin@curtin.edu.au 


\section{Abstract}

Background: The relationship between cannabis use and cognitive function in mid-life has rarely been examined despite verbal learning deficits in young adults. Method: A longitudinal cohort study of 1,897 Australians recruited at 40-46 years of age and followed up 4 years (94\%) and 8 years (87\%) later. Random effects regression was used to assess within- and between-person associations between cannabis use and cognitive function across waves of data, and examine whether age-related changes in cognitive performance were modified by cannabis use. The first list of the California Verbal Learning Test (immediate and delayed recall), Symbol Digit Modality Test, Digit Backwards, simple and choice reaction time tasks, were administered at each wave. The Spot-the-Word test was used to assess premorbid verbal ability. Self-reported cannabis use in the past year (no use, < weekly use, $\geq$ weekly use) was assessed at each wave. Findings: Participants who used cannabis $\geq$ weekly had worse immediate recall $(b=-0.68, p=0.014)$ and showed a trend toward worse delayed recall $(b=-0.55, p=0.062)$ compared to non-users after adjusting for correlates of cannabis use and premorbid verbal ability. These effects were due to between-person differences. There were no significant within-person associations between cannabis use and recall, nor was there evidence of greater cognitive decline in cannabis users with age.

Conclusions: Mid-life cannabis users had poorer verbal recall than non-users, but this was not related to their current level of cannabis use, and cannabis was not associated with accelerated cognitive decline.

Keywords: cannabis, marijuana, cognitive, memory, aging, substance abuse 


\section{INTRODUCTION}

Understanding the impact of cannabis use on cognitive function in mid-life adults is increasingly important. Cannabis is already consumed by an estimated 178 million people worldwide (United Nations Office on Drugs and Crime, 2015) and 13.1 million people are dependent on the drug (Degenhardt et al., 2013). However, its use is projected to rise significantly in older cohorts (50+ years) with the ageing of the baby-boomer generation (Colliver et al., 2006; Wu and Blazer, 2011). The medicalisation of cannabis is also likely to see increased use in older adults to treat chronic pain (Martin-Sanchez et al., 2009) and as an antiemetic in cancer treatment (Borgelt et al., 2013). For example, Pacula et al. (2015) cite 18 US states where legislation has been established around the medicinal use of cannabis, this trend beginning in California in 1996 with the establishment of medical marijuana dispensaries.

Most research on the relationship between cannabis use and cognitive function comes from studies of young adults (Becker et al., 2010; Block and Ghoneim, 1993; Carlin and Trupin, 1977; Croft et al., 2001; Dafters et al., 2004; Dougherty et al., 2013; Ehrenreich et al., 1999; Fried et al., 2002; Gouzoulis-Mayfrank et al., 2000; Pope et al., 1996; Rodgers, 2000; Solowij, 1995). A meta-analysis of this research found that cannabis use was associated with worse performance on verbal learning and memory (i.e., immediate and delayed recall on the Californian Verbal Learning Test and the Rey Auditory Verbal Learning Test), with effect sizes ranging between 0.21 and 0.27 , but not on tasks involving attention, executive function, motor function, reaction time or language ability (Grant et al., 2003). However, more recent research suggests deficits may also be present occur in other domains, including attention and concentration and abstract reasoning (Crane et al., 2013). Longitudinal studies have also found deficits relative to premorbid ability (Fried et al., 2005; Meier et al., 2012), including greater cognitive decline into adulthood (Meier et al., 2012). Although some performance 
decrements recover with cessation of cannabis use (Fried et al., 2005; Tait et al., 2011) full recovery is not always observed (Meier et al., 2012).

Few studies have examined how these cognitive deficits manifest in later adulthood, where they may be exacerbated by cumulative exposure to cannabis, interact with natural agerelated declines in processing speed (Anstey et al., 2014; Singh-Manoux et al., 2012), or arise from secondary adverse effects of cannabis on educational and vocational attainment (Horwood et al., 2010b) - both of which are protective against age-related cognitive decline (Anstey et al., 2013). Both Solowij et al. (2002) and Pope et al. (2001) found verbal learning deficits in older cannabis users (aged 32-55 years), compared to a non-using control group; however, Pope et al. (2001) found deficits remitted following a 28 day washout period from cannabis use, suggesting that deficits may be restricted to periods of heavy use (Pope et al., 2001).

In this paper we use an alternative approach to previous research by examining within-person changes in cognitive function that co-occur with changes in cannabis use in a longitudinal cohort. Within-person effects estimate the average change in an outcome (i.e., cognitive test performance) during time periods when an individual is exposed to a particular risk factor (i.e. cannabis use) relative to when they are not exposed (i.e. not using cannabis). This approach provides superior control for time-invariant factors (e.g., heritable traits, personality, sex) than statistical adjustment, and also reduces confounding by unmeasured time-invariant confounds (Gunasekara et al., 2014). It has been used to strengthen evidence for a causal relationship between substance use and various health and social outcomes (Fergusson et al., 2002; Livingston, 2011; McKetin et al., 2013). Time-varying factors can still need to be adjusted for because they can confound these types of analyses.

We assessed the relationship between current levels of cannabis use and cognitive functioning across three waves of data in a population-based longitudinal cohort of adults in their forties 
and examined whether deficits were restricted to current levels of cannabis use by testing within-person changes in cognitive performance during periods of cannabis use. We hypothesised (a) that heavy cannabis users would perform more poorly on tests of verbal recall; and (b) that this effect would be due to a significant within-person association between cannabis use and cognitive function, indicating worse cognitive function during periods of more frequent cannabis use relative to periods of no use. We also explored whether cannabis use modified age-related changes in cognitive performance, which could indicate early cognitive decline.

\section{MATERIAL AND METHODS}

\subsection{Participants and procedure}

Participants were 2,530 people aged 40-46 years old, who were recruited from the Personality and Total Health (PATH) through life cohort in 2000-2001. Participants were randomly drawn from the electoral roll of the Australian Capital Territory and Queanbeyan in Australia (Anstey et al., 2012). Voting is compulsory in Australia and therefore electoral roll samples provide a good reflection of the adult general population. The response rate was $64.6 \%$. A comparison with the Australian census data show that the final cohort was representative of the general population in terms of their marital and employment status, but that they were more educated (Anstey et al., 2012). Participants were followed up every four years, with $2,354(93 \%)$ re-interviewed at wave 2 , and 2,182 at wave $3(86 \%)$.

For this study, participants were excluded if they reported a history of head injury $(n=321)$, stroke or transient ischemic attack $(n=62)$ or epilepsy $(n=21)$. Similar to previous studies on cognitive function in this cohort (Tait et al., 2011), we excluded participants for whom English was a second language $(\mathrm{n}=210)$, because this was related to poor performance on verbal recall. A further 18 participants were excluded because they reported illicit 
psychostimulant use at either wave 2 or 3 (this was not assessed at wave 1), and one participant was excluded because they were missing data on cannabis use at all three waves. This left 1,897 participants in the final sample, with 1,774 followed up at wave 2 (94\%) and 1,653 followed up at wave $3(87 \%)$. Data on cannabis use was missing at seven observation points, giving a total of 5,317 observations across all three waves.

All participants were volunteers who provided informed consent prior to participation. The study was approved by the Australian National University's Human Research Ethics Committee.

\subsection{Measures}

Cannabis use: Past year cannabis use was assessed using the question "Have you used marijuana/hash in the past 12 months?" followed by the question "How often do you use marijuana/hash?" (once a week or more, once a month, every 1-4 months, once or twice a year, less often/no longer use). Based on these questions, participants were classified as either not using cannabis within the past year (non-users), using cannabis less than weekly use, or using cannabis weekly or more often.

Cognitive tests: All cognitive tests were administered at each wave. Immediate and delayed recall was assessed with components of the California Verbal Learning Test (Delis et al., 1987). Participants were read a list of 16 words from 4 taxonomic categories (e.g., fruits, tools), presented in unblocked order, and asked to immediately recall as many words as possible (immediate recall). This list was read once only. Following a short interval (i.e., completing a grip strength task), participants were again asked to recall as many words as possible (delayed recall).Working memory was assessed using the Digits Backwards subtest 
of the Wechsler Memory Scale, which involves reading a series of digits to the participant who is then required to recall them in reverse order (Wechsler, 1945). The Symbol-Digit Modalities Test (Smith, 1982) requires participants to substitute digits (1-9) with their corresponding symbol as fast as possible within a 90-second period; it involves attention, visual scanning and motor speed (Sheridan et al., 2006) and is sensitive to changes in cognitive function following mild head injury (Hinton-Bayre et al., 1997). Simple and choice reaction time was measured by getting the participant to press one of two buttons on the top of a small box (held in both hands), with their index fingers, in reaction to a red stimulus light located on the front of the box under each button. A green get-ready light was centred beneath these. The mean simple reaction time was taken from four blocks of 20 trials and the mean choice reaction time from two blocks of twenty trials. For simple reaction time participants used their right hand regardless of dominance. Premorbid verbal ability was assessed using the Spot-the-Word Task (Baddeley et al., 1993). This tests involves presenting the participant with 60 consecutive word pairs, each of which contains one real word and one word that is not real (e.g. 'flonty - xylophone'). The participant is required to point to the real word in the pair. The Spot-the-Word test is a robust measure of verbal intelligence which is resilient to deterioration with age (Baddeley et al., 1993) and mild head injury (Hinton-Bayre et al., 1997).

Time-invariant co-variates: Time invariant covariates were assessed at wave 1 and included age, sex, years of education, race (Caucasian vs. other) and past alcohol consumption. Past alcohol consumption was assessed by asking the participant the following questions about when they were drinking at their highest level over a period of three months or longer: "How often did you have a drink containing alcohol?" (monthly or less, 2 to 4 times a month, 2 to 3 times a week, 4 or more times a week) and "How many standard drinks did you have on a typical day when you were drinking?" ( 1 or 2,3 or 4,5 or 6,7 to 9,10 or more). 
Time-varying co-variates: Time-varying co-variates were measured at all three waves and included employment status (employed vs. not in the labour force), tobacco smoking (never, past and current) and alcohol consumption (Alcohol Use Disorders Identification Test (AUDIT) (Babor et al., 2001) score). Body mass index (BMI) was calculated using selfreported height and weight [weight $(\mathrm{kg}) /$ height $\left.(\mathrm{m})^{2}\right]$. Exercise was based on self-reported average hours or mild, moderate or vigorous exercise per week. Examples of mild exercise were walking, weeding; moderate exercise: dancing, cycling; and, vigorous exercise: running, squash. Depression and anxiety were based on scores of $\geq 5$ and $\geq 7$ on the Goldberg Depression and Anxiety Scales respectively (Goldberg et al., 1988); these cut points correctly classified $83 \%$ and $85 \%$ of people with depressive and generalised anxiety disorders in this cohort respectively (Kiely and Butterworth, 2015).

\subsection{Statistical analysis}

Analyses were conducted using Stata Special Edition version 14.1 (Statacorp, College Station, TX). Analyses were carried out across all three waves of data.

To identify potential confounders we examined the relationship between cannabis use and each participant characteristic using a series of regression models where the participant characteristic was the outcome variable and level of cannabis use was the predictor (no cannabis use [0], < weekly use [1], $\geq$ weekly use [2]). Linear regression models were used for continuous outcomes and logistic regression models were used for categorical outcomes. Variables with multiple categories were analysed by creating dichotomous variables that compared each category to the lowest (reference) category. When the outcome was timevarying, random effects regression was used with a random intercept to allow clustering of individual-level data on repeated measures across waves of assessment. Where a random intercept could not be fitted because the outcome did not vary across repeats, robust standard errors were used. The results of these analyses are shown in Table 1. 
To examine the relationship between cannabis use and cognitive function we conducted a series of linear random effects regressions, with the time-varying cognitive test measure as the outcome variable and the time-varying level of cannabis use (no use [0] - reference category, $<$ weekly use [1], $\geq$ weekly use [2]) as a categorical predictor variable. These models included a random intercept to allow clustering of individual-level data on repeated assessments. All models included study wave (wave 1 [0], wave 2 [1], wave 3 [2]). To assess whether cannabis use modified age-related changes in cognitive function, an interaction term between time-varying cannabis use level (no use [0], < weekly use [1], $\geq$ weekly use [2]) and wave (wave 1 [0], wave 2 [1], wave 3 [2]) was included in the model. Models were adjusted for factors significantly associated with cannabis use (age at baseline, sex, unemployment, years of education, tobacco smoking, current AUDIT score, heaviest past drinking (4+ times/week and number of drinks/day), BMI, depression and premorbid verbal ability (Spot the Word score)). For cognitive tests where there was a significant relationship between test performance and cannabis use, subsequent within-person and between-person effects of cannabis on test performance were conducted using Stata's fixed and between effects estimator options respectively. Mean and 95\% confidence intervals for test scores for each wave were based on predicted margins from adjusted models.

Neither loss to follow-up nor missing data on cognitive tests (between 5 and 82 cases per test at each follow-up) were significantly correlated with cannabis use category $(\mathrm{p}>0.05$, analyses not shown) and so data were assumed to be missing at random and excluded from the analysis. All tests were two-sided with significance set at $\mathrm{p}<0.05$. 


\section{RESULTS}

\subsection{Characteristics of participants at baseline}

Participants were English speaking (100\%), mostly Caucasian (98\%) and employed (91\%); $16 \%$ were current tobacco smokers and $14 \%$ exceeded the cut-off of $\geq 8$ for risky drinking on the AUDIT (Table 1). Ten per cent of the sample $(n=576)$ had used cannabis at one of the three waves, with cannabis use reported at $6 \%$ of all assessments $(\mathrm{n}=331)$, and with $2 \%(\mathrm{n}=$ 106) involving using cannabis weekly or more often. Amongst participants who had used cannabis, $31 \%(\mathrm{n}=176)$ of observations represented a change in cannabis use category since the previous wave. Cannabis use was associated with being younger, male, not employed, having fewer years of education, smoking tobacco, lower BMI, greater alcohol consumption and depression (Table 1).

\subsection{Relationship between cannabis use and cognitive performance}

The unadjusted relationship between cannabis use and cognitive test performance across all three waves is shown in Table 2. Cannabis use was associated in a dose-related fashion with lower scores on immediate and delayed recall. It was also related to lower premorbid verbal ability (scores on the Spot the Word test). Cannabis use was not related to other test scores.

\subsection{Between-versus within-person effects for cannabis use}

Table 3 shows the relationship between cannabis use and verbal recall, overall, and for within- and between-person effects separately. Significant overall and between-person effects were found for weekly or greater cannabis use on immediate and delayed recall. Betweenperson effects were attenuated by adjustment for factors associated with cannabis use (i.e. age, sex, years education, employment, tobacco smoking, AUDIT score, heaviest past drinking, BMI and depression) and Spot the Word test scores, but using cannabis weekly or more often remained significantly associated with lower test scores on immediate recall (Table 3). The adjusted difference between weekly or greater cannabis use and no cannabis 
use was 1.2 and 1.1 words less than for no cannabis use on immediate and delayed recall respectively (or $0.55 \mathrm{SD}$ and $0.44 \mathrm{SD}$ respectively).

Within-person effects for cannabis use on immediate and delayed recall were not significant (Table 3), suggesting no significant difference in immediate or delayed recall during waves when cannabis using participants were using cannabis compared to waves when they were not using the drug.

\subsection{Changes in cognitive performance with age}

Changes in recall over the three waves of assessment, and interactions between cannabis use and wave of assessment, are shown in Table 3. Over the three waves there was small but significant improvement in immediate recall and delayed recall; however, there were no significant interaction effects between cannabis use level and wave, for either immediate recall or delayed recall, indicating that cannabis use did not significantly modify changes in recall that occurred with older age. There were no significant interaction effects between wave by cannabis use level for other cognitive tests. The predicted mean immediate and delayed recall scores for each wave, adjusted for correlates of cannabis use and premorbid verbal ability, are shown in Figure 1.

\section{DISCUSSION}

The finding that mid-life cannabis users has worse verbal recall is consistent with past research in young adults (Grant et al., 2003); however, this was only evident for a betweenperson effect, reflecting an overall average lower performance of heavy cannabis users relative to people who do not use the drug. The lack of a significant within-person effect of cannabis use on verbal recall indicates that verbal recall was no worse when people were using cannabis weekly or more often compared to when they were not using cannabis at all. This result is not consistent with cannabis-related deficits being due to the acute 
pharmacological effects of THC, as suggested by Pope et al. (2001) and others (Hanson et al., 2010), or that deficits recover with abstinence (Meier et al., 2012; Tait et al., 2011). Instead, our finding suggests that worse recall in heavy cannabis users is not significantly related to current levels of cannabis use. There are several possible interpretations of this result, as outline below.

First, decrements in verbal recall could reflect a lasting effect of cannabis use that does not recover with abstinence. This interpretation of the data would be consistent with a growing body of evidence that exposure to cannabis during adolescence can produce lasting changes in brain morphology (Becker et al., 2010; Carey et al., 2015; Mashhoon et al., 2015; Shollenbarger et al., 2015) and cognitive function (Becker et al., 2010; Meier et al., 2012; Schneider and Koch, 2003). It may be that mid-life cannabis users are suffering lasting effects from exposure to the drug during this critical period in adolescent brain development. The failure to find a temporal relationship between current levels of cannabis use and cognitive function could be because the adult brain is relatively more resistant to cannabis-induced neurotoxicity (Schneider and Koch, 2003) or the lack of a close temporal relationship between cannabis use/intoxication and cognitive testing in our study.

A second explanation for the lack of a temporal relationship between cannabis use and worse recall is that cannabis use may have a lasting effect on cognitive function via its adverse effects on outcomes in early adulthood, these including lower educational achievement (Horwood et al., 2010a; Horwood et al., 2010b), lower income and greater welfare dependence (Horwood et al., 2010a). Although we adjusted for a range of other variables that could impact on cognitive function (premorbid verbal ability, schooling, currently employment, alcohol and tobacco consumption, body mass index, exercise, anxiety and depression) there may have been residual confounding by such factors, or confounding by other unmeasured factors. 
A third possibility is that verbal recall deficits may pre-date cannabis use, or that the two conditions may result from a comorbid vulnerability (e.g. shared genetic or familial factors). Evidence to support this possibility comes from a study by Pagliaccio et al. (2015) who examined brain volume in cannabis discordant twin/sibling couples, and found that the relationship between cannabis use and brain volume was largely owing to shared genetic factors rather than exposure to cannabis.

Deficits in cognitive function could also be a reflection of the elevated risk of psychotic disorders seen in cannabis users (Hall and Degenhardt, 2008), with cannabis-related brain changes being correlated with psychotic symptoms (Yucel et al., 2008). Psychotic disorders are also characterised by deficits in episodic memory (Fioravanti et al., 2012; Schaefer et al., 2013). These deficits are thought to be a neurodevelopmental phenomenon that conveys vulnerability to psychotic disorders (Bora and Murray, 2014; Bossong and Niesink, 2010; Bowie and Harvey, 2006; Fusar-Poli et al., 2012; Schneider and Koch, 2003). Therefore, enduring cognitive deficits in cannabis users could reflect a pre-existing vulnerability to psychosis in a subset of this population.

Participants who used cannabis weekly or more often recalled a mean of around one word less (a deficit of around one half of a standard deviation less) than non-cannabis users on a list of 16 words. According to the DSM-5 (American Psychiatric Association, 2013), a mild neurocognitive disorder is characterised by cognitive performance that is least one standard deviation below the norm, while dementia requires performance that is at least two standard deviations below the norm. Therefore, the average recall deficits seen in people who use cannabis weekly or more often appear to fall within the normal range of cognitive functioning, and thus do not reflect a clinically significant impairment. However, the net effect of this decrement at a population level may be important. Verbal recall is a measure of episodic memory, which is the first cognitive symptom of Alzheimer's disease (Gainotti et al., 2014), suggesting mid-life cannabis users are a high risk group for dementia — a risk 
could be circumvented via cognitive remediation and reduction of known modifiable risk factors for dementia, such as tobacco smoking (Anstey et al., 2013).

In this study we did not find evidence that cannabis was related to early decline in verbal recall. However, we had limited statistical power to detect such an effect due to the small number of heavy cannabis users in this sample. We also found no evidence of verbal recall decline in the overall sample, suggesting that it may be too early in the life-span to detect any effects of cannabis on cognitive decline. Being a highly educated sample, cognitive reserve may also be mitigating against any deleterious effect that cannabis may have on cognitive decline. Effects on cognitive decline, should they exist, may become apparent with older age.

\section{Limitations and considerations}

The key strength of our findings is that they are based on a large general population sample and we were able to adjust for a wide variety of lifestyle and health factors that are related to cognitive function. The PATH cohort provides a unique opportunity to examine the relationship between cannabis use and cognitive function in mid-life adults, with other population-based cannabis research focussing on younger cohorts (e.g., Fergusson and Horwood (2000)). However, an inherent limitation of large-scale epidemiological studies is reliance on self-report, and detailed measurement is often not possible. We did not have a detailed history of participant's cannabis use, nor did we have information on how recently cannabis was used prior to testing, factors that may have obscured the relationship between current cannabis use levels and cognitive function. Measures of alcohol and tobacco use were more comprehensive, including both current and past use, but the possibility of residual confounding remains. Although we relied on self-reported illicit substance use, this is reliable when participant confidentiality is assured (Darke, 1998), as it was in this study.

A further consideration is that immediate and delayed recall were assessed using components of the California Verbal Learning Test rather than the full test. Therefore scores on the test 
cannot be directly compared to normative data to assess impairment. Also, the delayed recall was assessed after only a brief interval rather than the longer delay normally used to assess delayed recall in the California Verbal Learning Test. This could explain discrepancies between our results and those of previous studies. A longer delay period may have been more sensitive to deficits in delayed memory, while the absence of such a delay may have reduced our capacity to detect cannabis-related deficits in delayed recall.

\section{Conclusion}

Mid-life cannabis use ( $\geq$ weekly use) was associated with worse verbal episodic memory as reflected by poor verbal recall. Deficits in verbal recall may place cannabis users at elevated risk of cognitive decline in later life, or even dementia, as episodic memory decline is the first cognitive symptom of Alzheimer's disease (Gainotti et al., 2014). Further research is needed to establish whether these decrements are due to lasting brain changes associated with cannabis use or other correlates of cannabis use (e.g. genetics, vulnerability to psychosis). 
Acknowledgments: PATH was funded by National Health and Medical Research Council Grants 229936, 973302, 179839, 179805, 418039, 1002160. Kaarin Anstey is funded by NHMRC Fellowships No.1002560 and Nicolas Cherbuin by ARC Fellowship No. 12010227. Rebecca McKetin is funded by a Curtin Research Fellowship. The authors are grateful to Patricia Jacomb, Karen Maxwell, Peter Butterworth, Simon Easteal, Helen Christensen and the PATH interviewers.

Declaration of interest: Nil. 


\section{REFERENCES}

American Psychiatric Association, 2013. Diagnostic and Statistical Manual of Mental Disorders, Fifth Edition. American Psychiatric Association, Web: dsm.psychiatryonline.org, Arlington, VA.

Anstey, K.J., Cherbuin, N., Herath, P.M., 2013. Development of a new method for assessing global risk of Alzheimer's disease for use in population health approaches to prevention. Prev Sci 14, 411-421.

Anstey, K.J., Christensen, H., Butterworth, P., Easteal, S., Mackinnon, A., Jacomb, T., Maxwell, K., Rodgers, B., Windsor, T., Cherbuin, N., Jorm, A.F., 2012. Cohort profile: the PATH through life project. Int J Epidemiol 41, 951-960.

Anstey, K.J., Sargent-Cox, K., Garde, E., Cherbuin, N., Butterworth, P., 2014. Cognitive development over 8 years in midlife and its association with cardiovascular risk factors. Neuropsychology 28, 653-665.

Babor, T.F., Higgins-Biddle, J.C., Saunders, J.B., Monteiro, M.G., 2001. The Alcohol Use Disorders Identification Test: Guidelines for Use in Primary Care., Geneva, Switzerland.

Baddeley, A., Emslie, H., Nimmo-Smith, I., 1993. The Spot-the-Word test: A robust estimate of verbal intelligence based on lexical decision. British Journal of Clinical Psychology 32, 55-65.

Becker, B., Wagner, D., Gouzoulis-Mayfrank, E., Spuentrup, E., Daumann, J., 2010. The impact of early-onset cannabis use on functional brain correlates of working memory. Prog Neuropsychopharmacol Biol Psychiatry 34, 837-845.

Block, R.I., Ghoneim, M.M., 1993. Effects of chronic marijuana use on human cognition. Psychopharmacology (Berl) 110, 219-228. 
Bora, E., Murray, R.M., 2014. Meta-analysis of cognitive deficits in ultra-high risk to psychosis and first-episode psychosis: do the cognitive deficits progress over, or after, the onset of psychosis? Schizophr Bull 40, 744-755.

Borgelt, L.M., Franson, K.L., Nussbaum, A.M., Wang, G.S., 2013. The pharmacologic and clinical effects of medical cannabis. Pharmacotherapy 33, 195-209.

Bossong, M.G., Niesink, R.J., 2010. Adolescent brain maturation, the endogenous cannabinoid system and the neurobiology of cannabis-induced schizophrenia. Progress in neurobiology 92, 370-385.

Bowie, C.R., Harvey, P.D., 2006. Cognitive deficits and functional outcome in schizophrenia. Neuropsychiatric Disease and Treatment 2, 531-536.

Carey, S.E., Nestor, L., Jones, J., Garavan, H., Hester, R., 2015. Impaired learning from errors in cannabis users: Dorsal anterior cingulate cortex and hippocampus hypoactivity. Drug Alcohol Depend 155, 175-182.

Carlin, A.S., Trupin, E.W., 1977. The Effect of Long-Term Chronic Marijuana Use on Neuropsychological Functioning. International Journal of the Addictions 12, 617624.

Colliver, J.D., Compton, W.M., Gfroerer, J.C., Condon, T., 2006. Projecting drug use among aging baby boomers in 2020. Ann Epidemiol 16, 257-265.

Crane, N.A., Schuster, R.M., Fusar-Poli, P., Gonzalez, R., 2013. Effects of cannabis on neurocognitive functioning: recent advances, neurodevelopmental influences, and sex differences. Neuropsychol Rev 23, 117-137.

Croft, R.J., Mackay, A.J., Mills, A.T., Gruzelier, J.G., 2001. The relative contributions of ecstasy and cannabis to cognitive impairment. Psychopharmacology (Berl) 153, 373379. 
Dafters, R.I., Hoshi, R., Talbot, A.C., 2004. Contribution of cannabis and MDMA ("ecstasy") to cognitive changes in long-term polydrug users. Psychopharmacology (Berl) 173, 405-410.

Darke, S., 1998. Self-report among injecting drug users: a review.[see comment]. Drug Alcohol Depend 51, 253-263; discussion 267-258.

Degenhardt, L., Ferrari, A.J., Calabria, B., Hall, W.D., Norman, R.E., McGrath, J., Flaxman, A.D., Engell, R.E., Freedman, G.D., Whiteford, H.A., Vos, T., 2013. The global epidemiology and contribution of cannabis use and dependence to the global burden of disease: results from the GBD 2010 study. PLoS ONE 8, e76635.

Delis, D.C., Kramer, J.H., Kaplan, E., Ober, B.A., 1987. CVLT, California Verbal Learning Test: Adult Version: Manual. Psychological Corporation.

Dougherty, D.M., Mathias, C.W., Dawes, M.A., Furr, R.M., Charles, N.E., Liguori, A., Shannon, E.E., Acheson, A., 2013. Impulsivity, attention, memory, and decisionmaking among adolescent marijuana users. Psychopharmacology (Berl) 226, 307 319.

Ehrenreich, H., Rinn, T., Kunert, H.J., Moeller, M.R., Poser, W., Schilling, L., Gigerenzer, G., Hoehe, M.R., 1999. Specific attentional dysfunction in adults following early start of cannabis use. Psychopharmacology (Berl) 142, 295-301.

Fergusson, D.M., Horwood, L.J., 2000. Cannabis use and dependence in a New Zealand birth cohort. New Zealand Medical Journal 113, 156-158.

Fergusson, D.M., Swain-Campbell, N.R., Horwood, L.J., 2002. Deviant peer affiliations, crime and substance use: a fixed effects regression analysis. J Abnorm Child Psychol $30,419-430$.

Fioravanti, M., Bianchi, V., Cinti, M.E., 2012. Cognitive deficits in schizophrenia: an updated metanalysis of the scientific evidence. BMC Psychiatry 12, 1-20. 
Fried, P., Watkinson, B., James, D., Gray, R., 2002. Current and former marijuana use: preliminary findings of a longitudinal study of effects on IQ in young adults. Cmaj $166,887-891$.

Fried, P.A., Watkinson, B., Gray, R., 2005. Neurocognitive consequences of marihuana--a comparison with pre-drug performance. Neurotoxicol Teratol 27, 231-239.

Fusar-Poli, P., Deste, G., Smieskova, R., et al., 2012. Cognitive functioning in prodromal psychosis: A meta-analysis. Archives of general psychiatry 69, 562-571.

Gainotti, G., Quaranta, D., Vita, M.G., Marra, C., 2014. Neuropsychological predictors of conversion from mild cognitive impairment to Alzheimer's disease. J Alzheimers Dis $38,481-495$.

Goldberg, D., Bridges, K., Duncan-Jones, P., Grayson, D., 1988. Detecting anxiety and depression in general medical settings. BMJ 297, 897-899.

Gouzoulis-Mayfrank, E., Daumann, J., Tuchtenhagen, F., Pelz, S., Becker, S., Kunert, H.J., Fimm, B., Sass, H., 2000. Impaired cognitive performance in drug free users of recreational ecstasy (MDMA). J Neurol Neurosurg Psychiatry 68, 719-725.

Grant, I., Gonzalez, R., Carey, C.L., Natarajan, L., Wolfson, T., 2003. Non-acute (residual) neurocognitive effects of cannabis use: a meta-analytic study. J Int Neuropsychol Soc 9, 679-689.

Gunasekara, F.I., Richardson, K., Carter, K., Blakely, T., 2014. Fixed effects analysis of repeated measures data. Int J Epidemiol 43, 264-269.

Hall, W., Degenhardt, L., 2008. Cannabis use and the risk of developing a psychotic disorder. World Psychiatry 7, 68-71.

Hanson, K.L., Winward, J.L., Schweinsburg, A.D., Medina, K.L., Brown, S.A., Tapert, S.F., 2010. Longitudinal study of cognition among adolescent marijuana users over three weeks of abstinence. Addict Behav 35, 970-976. 
Hinton-Bayre, A.D., Geffen, G., McFarland, K., 1997. Mild head injury and speed of information processing: a prospective study of professional rugby league players. J Clin Exp Neuropsychol 19, 275-289.

Horwood, L.J., Fergusson, D.M., Hayatbakhsh, M.R., Najman, J.M., Coffey, C., Patton, G.C., Silins, E., Hutchinson, D.M., 2010a. Cannabis use and educational achievement: findings from three Australasian cohort studies. Drug Alcohol Depend 110, 247-253.

Horwood, L.J., Fergusson, D.M., Hayatbakhsh, M.R., Najman, J.M., Coffey, C., Patton, G.C., Silins, E., Hutchinson, D.M., 2010b. Cannabis use and educational achievement: findings from three Australasian cohort studies. Drug Alcohol Depend 110, 247-253.

Kiely, K.M., Butterworth, P., 2015. Validation of four measures of mental health against depression and generalized anxiety in a community based sample. Psychiatry Res $225,291-298$.

Livingston, M., 2011. A longitudinal analysis of alcohol outlet density and domestic violence. Addiction 106, 919-925.

Martin-Sanchez, E., Furukawa, T.A., Taylor, J., Martin, J.L., 2009. Systematic review and meta-analysis of cannabis treatment for chronic pain. Pain Med 10, 1353-1368.

Mashhoon, Y., Sava, S., Sneider, J.T., Nickerson, L.D., Silveri, M.M., 2015. Cortical thinness and volume differences associated with marijuana abuse in emerging adults. Drug and Alcohol Dependence 155, 275-283.

McKetin, R., Lubman, D.I., Baker, A.L., Dawe, S., Ali, R.L., 2013. Dose-related psychotic symptoms in chronic methamphetamine users: Evidence from a prospective longitudinal study. JAMA psychiatry 70, 319-324.

Meier, M.H., Caspi, A., Ambler, A., Harrington, H., Houts, R., Keefe, R.S.E., McDonald, K., Ward, A., Poulton, R., Moffitt, T.E., 2012. Persistent cannabis users show neuropsychological decline from childhood to midlife. Proceedings of the National Academy of Sciences 109, E2657-E2664. 
Pacula, R.L., Powell, D., Heaton, P., Sevigny, E.L., 2015. Assessing the Effects of Medical Marijuana Laws on Marijuana Use: The Devil is in the Details. Journal of Policy Analysis and Management 34, 7-31.

Pagliaccio, D., Barch, D.M., Bogdan, R., Wood, P.K., Lynskey, M.T., Heath, A.C., Agrawal, A., 2015. Shared Predisposition in the Association Between Cannabis Use and Subcortical Brain Structure. JAMA psychiatry 72, 994-1001.

Pope, H.G., Jr, Gruber, A.J., Hudson, J.I., Huestis, M.A., Yurgelun-Todd, D., 2001. Neuropsychological performance in long-term cannabis users. Archives of general psychiatry 58, 909-915.

Pope, H.G., Jr, Yurgelun-Todd, D., 1996. THe residual cognitive effects of heavy marijuana use in college students. JAMA 275, 521-527.

Rodgers, J., 2000. Cognitive performance amongst recreational users of "ecstasy". Psychopharmacology (Berl) 151, 19-24.

Schaefer, J., Giangrande, E., Weinberger, D.R., Dickinson, D., 2013. The global cognitive impairment in schizophrenia: Consistent over decades and around the world. Schizophr Res 150, 42-50.

Schneider, M., Koch, M., 2003. Chronic pubertal, but not adult chronic cannabinoid treatment impairs sensorimotor gating, recognition memory, and the performance in a progressive ratio task in adult rats. Neuropsychopharmacology 28, 1760-1769.

Sheridan, L.K., Fitzgerald, H.E., Adams, K.M., Nigg, J.T., Martel, M.M., Puttler, L.I., Wong, M.M., Zucker, R.A., 2006. Normative Symbol Digit Modalities Test performance in a community-based sample. Archives of Clinical Neuropsychology 21, 23-28.

Shollenbarger, S.G., Price, J., Wieser, J., Lisdahl, K., 2015. Impact of cannabis use on prefrontal and parietal cortex gyrification and surface area in adolescents and emerging adults. Developmental Cognitive Neuroscience 16, 46-53. 
Singh-Manoux, A., Kivimaki, M., Glymour, M.M., Elbaz, A., Berr, C., Ebmeier, K.P., Ferrie, J.E., Dugravot, A., 2012. Timing of onset of cognitive decline: results from Whitehall II prospective cohort study.

Smith, A., 1982. Symbol Digit Modalities Test (SDMT) Manual. Western Psychological Services, Los Angeles.

Solowij, N., 1995. Do cognitive impairments recover following cessation of cannabis use ? Life Sciences 56, 2119-2126.

Solowij, N., Stephens, R.S., Roffman, R.A., Babor, T., Kadden, R., Miller, M., Christiansen, K., McRee, B., Vendetti, J., 2002. Cognitive functioning of long-term heavy cannabis users seeking treatment. JAMA 287, 1123-1131.

Tait, R.J., Mackinnon, A., Christensen, H., 2011. Cannabis use and cognitive function: 8-year trajectory in a young adult cohort. Addiction 106, 2195-2203.

United Nations Office on Drugs and Crime, 2015. World Drug Report 2014. United Nations, New York.

Wechsler, D., 1945. A standardized memory scale for clinical use. The Journal of Psychology 19, 87-95.

Wu, L.-T., Blazer, D.G., 2011. Illicit and Nonmedical Drug Use Among Older Adults: A Review. Journal of aging and health 23, 481-504.

Yucel, M., Solowij, N., Respondek, C., Whittle, S., Fornito, A., Pantelis, C., Lubman, D.I., 2008. Regional brain abnormalities associated with long-term heavy cannabis use. Archives of general psychiatry 65, 694-701. 
Table 1. Relationship between cannabis use and participant characteristics across all three waves

\begin{tabular}{|c|c|c|c|}
\hline & $\begin{array}{l}\text { No use } \\
(\mathrm{n}=4,986 \mathrm{PY})\end{array}$ & $\begin{array}{l}<\text { weekly use } \\
(\mathrm{n}=225 \mathrm{PY})\end{array}$ & $\begin{array}{l}\geq \text { weekly } \\
(\mathrm{n}=106 \mathrm{PY})\end{array}$ \\
\hline & Mean $(\mathrm{SD}) / \mathrm{n}(\%)$ & Mean $(\mathrm{SE}) / \mathrm{n}(\%)$ & Mean $(\mathrm{SE}) / \mathrm{n}(\%)$ \\
\hline \multicolumn{4}{|c|}{ Demographics at baseline } \\
\hline Age & $42.6(1.5)$ & $42.3(1.5)^{* *}$ & $42.7(1.4)$ \\
\hline Male & $2,119(42.5)$ & $130(57.8) * * *$ & $74(69.8) * * *$ \\
\hline Caucasian & $4,876(97.8)$ & $221(98.2)$ & $105(99.1)$ \\
\hline Employed & $4,553(90.9)$ & $204(90.7)$ & $89(84.8)$ \\
\hline Years of education & $14.5(2.3)$ & $14.5(2.1)$ & $13.9(2.5) * *$ \\
\hline \multicolumn{4}{|l|}{ Heaviest past drinking } \\
\hline $\begin{array}{l}\text { 4+ times per week } \\
\text { No. drinks/day }\end{array}$ & $1,770(35.5)$ & $122(54.2)^{* * *}$ & $59(55.7) * * *$ \\
\hline Up to 2 drinks & $2,305(46.4)$ & $52(23.4) * * *$ & $26(24.5) * * *$ \\
\hline 3-4 drinks & $1,389(28.0)$ & $44(19.8)^{* *}$ & $29(27.4)$ \\
\hline 5-9 drinks & $1,079(21.7)$ & $105(47.3)^{* * *}$ & $35(33.0)^{*}$ \\
\hline $10+$ drinks & $196(3.9)$ & $21(9.5) * * *$ & $16(15.1)^{* * *}$ \\
\hline AUDIT score & $4.2(3.6)$ & $7.1(5.2)^{* * *}$ & $6.6(5.7)^{* * *}$ \\
\hline \multicolumn{4}{|l|}{ Tobacco smoking } \\
\hline Non-smoker & $2,768(55.6)$ & $47(20.9)$ & $12(11.3)$ \\
\hline Past smoker & $1,544(31.0)$ & $89(39.6)$ & $25(23.6) * * *$ \\
\hline Current smoker & $668(13.4)$ & $89(39.6) * * *$ & $69(65.1)^{* * *}$ \\
\hline Body mass index & $27.0(5.1)$ & $26.4(4.4)^{*}$ & $25.7(3.9)^{* *}$ \\
\hline \multicolumn{4}{|l|}{ Exercise } \\
\hline Low & $1,815(37.6)$ & $83(37.9)$ & $37(35.2)$ \\
\hline Moderate & $1,891(39.2)$ & $82(37.4)$ & $42(40.0)$ \\
\hline High & $1,123(23.3)$ & $54(24.7)$ & $26(24.8)$ \\
\hline Depression & 854 (17.2) & $61(27.4) * * *$ & $21(19.8)$ \\
\hline Anxiety & 778 (15.7) & $40(17.9)$ & $10(9.4)$ \\
\hline
\end{tabular}

$* \mathrm{p}<.05, * * \mathrm{p}<.01 * * * \mathrm{p}<.001 . \mathrm{P}$ values reflect comparisons of each participant characteristic for $<$ weekly use and $\geq$ weekly use relative to no use across all waves of data. Comparisons were made for person years (PY) using regressions with robust standard errors for time-invariant characteristics and random effects regressions for time-varying characteristics. 
Table 2. Relationship between level of cannabis use and cognitive test scores across all three waves

\begin{tabular}{|c|c|c|c|c|c|c|c|}
\hline & \multirow{2}{*}{$\begin{array}{l}\text { No use }(\mathrm{n}=5,006 \mathrm{PY}) \\
\text { Mean }(\mathrm{SD})\end{array}$} & \multicolumn{3}{|c|}{$<$ weekly use $(\mathrm{n}=225 \mathrm{PY})$} & \multicolumn{3}{|c|}{$\geq$ weekly $(\mathrm{n}=106 \mathrm{PY})$} \\
\hline & & Mean (SD) & $\begin{array}{l}\text { Coefficient } \\
\text { (SE) }\end{array}$ & $\mathrm{P}$ value & Mean (SD) & $\begin{array}{l}\text { Coefficient } \\
\text { (SE) }\end{array}$ & $\mathrm{P}$ value \\
\hline Spot the word & $51.4(5.0)$ & $52.2(4.1)$ & $0.01(0.23)$ & .975 & $51.1(6.1)$ & $-0.92(0.43)$ & .035 \\
\hline Immediate recall & $8.1(2.2)$ & $7.7(2.0)$ & $-0.34(0.14)$ & .017 & $6.8(2.1)$ & $-1.00(0.24)$ & $<.001$ \\
\hline Delayed recall & $7.4(2.5)$ & $6.9(2.3)$ & $-0.32(0.15)$ & .035 & $6.0(2.2)$ & $-0.91(0.26)$ & $<.001$ \\
\hline Digit span backwards & $5.6(2.3)$ & $5.6(2.5)$ & $-0.21(0.14)$ & .125 & $5.2(2.4)$ & $-0.38(0.23)$ & .105 \\
\hline Symbol Digit Modality Test & $60.4(8.8)$ & $59.7(8.5)$ & $0.14(0.43)$ & .741 & $58.5(7.9)$ & $0.35(0.79)$ & .657 \\
\hline Mean simple reaction time (ms) & $233.8(42.0)$ & $\begin{array}{l}230.8 \\
(49.6)\end{array}$ & $-2.57(2.70)$ & .341 & $233.4(37.5)$ & $-1.58(4.59)$ & .731 \\
\hline Choice reaction time (ms) & $290.8(40.2)$ & $\begin{array}{l}291.6 \\
(41.8)\end{array}$ & $1.25(2.43)$ & .608 & $298.6(36.3)$ & $1.54(4.21)$ & .715 \\
\hline
\end{tabular}

Coefficients reflect comparisons with no use from random effects regressions across all three waves of data 
Table 3. Random effect regression models showing the relationship between cannabis use and recall

\begin{tabular}{|c|c|c|c|c|c|c|c|c|}
\hline & \multicolumn{4}{|l|}{ Immediate recall } & \multicolumn{4}{|l|}{ Delayed recall } \\
\hline & \multicolumn{2}{|l|}{ Unadjusted } & \multicolumn{2}{|l|}{ Adjusted $^{\mathrm{a}}$} & \multicolumn{2}{|l|}{ Unadjusted } & \multicolumn{2}{|l|}{ Adjusted $^{\mathrm{a}}$} \\
\hline & Coefficient (SE) & $\mathrm{P}$ value & Coefficient (SE) & $\mathrm{P}$ value & Coefficient (SE) & $\mathrm{P}$ value & Coefficient (SE) & $P$ value \\
\hline \multicolumn{9}{|l|}{ Random effects } \\
\hline \multicolumn{9}{|l|}{ Cannabis use } \\
\hline \multicolumn{9}{|l|}{ No use (ref) } \\
\hline$<$ wkly use & $-0.29(0.16)$ & .066 & $-0.28(0.16)$ & .092 & $-0.23(0.17)$ & .162 & $-0.16(0.17)$ & .338 \\
\hline Wkly+ use & $-1.00(0.24)$ & $<.001$ & $-0.68(0.27)$ & .014 & $-0.77(0.28)$ & .006 & $-0.55(0.29)$ & .062 \\
\hline Wave & $0.09(0.03)$ & .001 & $0.67(0.03)$ & .024 & $0.09(0.03)$ & .001 & $0.06(0.03)$ & .051 \\
\hline Wave $\mathrm{x}$ cannabis use & $-0.02(0.09)$ & .781 & $0.00(0.09)$ & .995 & $-0.07(0.09)$ & .419 & $-0.08(0.09)$ & .374 \\
\hline \multicolumn{9}{|l|}{ Between-person effects } \\
\hline \multicolumn{9}{|l|}{ Cannabis use } \\
\hline \multicolumn{9}{|l|}{ No use (ref) } \\
\hline$<$ wkly use & $-0.42(0.34)$ & .220 & $-0.61(0.35)$ & .055 & $-0.61(0.38)$ & .112 & $-0.59(0.36)$ & .096 \\
\hline Wkly+ use & $-1.52(0.61)$ & .013 & $-1.23(0.54)$ & .021 & $-1.50(0.69)$ & .029 & $-1.09(0.60)$ & .070 \\
\hline Wave & $0.78(0.16)$ & $<.001$ & $0.37(0.12)$ & .002 & $0.90(0.18)$ & $<.001$ & $0.31(0.14)$ & .021 \\
\hline Wave $\mathrm{x}$ cannabis use & $0.04(0.32)$ & .891 & $0.17(0.26)$ & .511 & $0.01(0.36)$ & .969 & $0.09(0.29)$ & .768 \\
\hline \multicolumn{9}{|l|}{ Within-person effects } \\
\hline \multicolumn{9}{|l|}{ Cannabis use } \\
\hline \multicolumn{9}{|l|}{ No use (ref) } \\
\hline$<$ wkly use & $-0.11(0.19)$ & .553 & $-0.10(0.20)$ & .604 & $0.02(0.19)$ & .924 & $0.02(0.20)$ & .933 \\
\hline Wkly+ use & $-0.32(0.36)$ & .385 & $-0.21(0.41)$ & .598 & $-0.07(0.37)$ & .854 & $-0.13(0.41)$ & .757 \\
\hline Wave & $0.08(0.03)$ & .005 & $0.08(0.03)$ & .014 & $0.08(0.03)$ & .006 & $0.07(0.03)$ & .022 \\
\hline Wave $\mathrm{x}$ cannabis use & $-0.02(0.03)$ & 0.822 & $0.01(0.09)$ & .995 & $-0.07(0.09)$ & .463 & $-0.07(0.10)$ & .473 \\
\hline
\end{tabular}

${ }^{a}$ Adjusted for age at baseline, sex, unemployment, years of education, tobacco smoking, AUDIT score, heaviest past drinking (4+ times/week and no. drinks/day), BMI, depression and premorbid verbal ability (Spot the Word score). Note non-time varying covariates omitted from within-person models. 


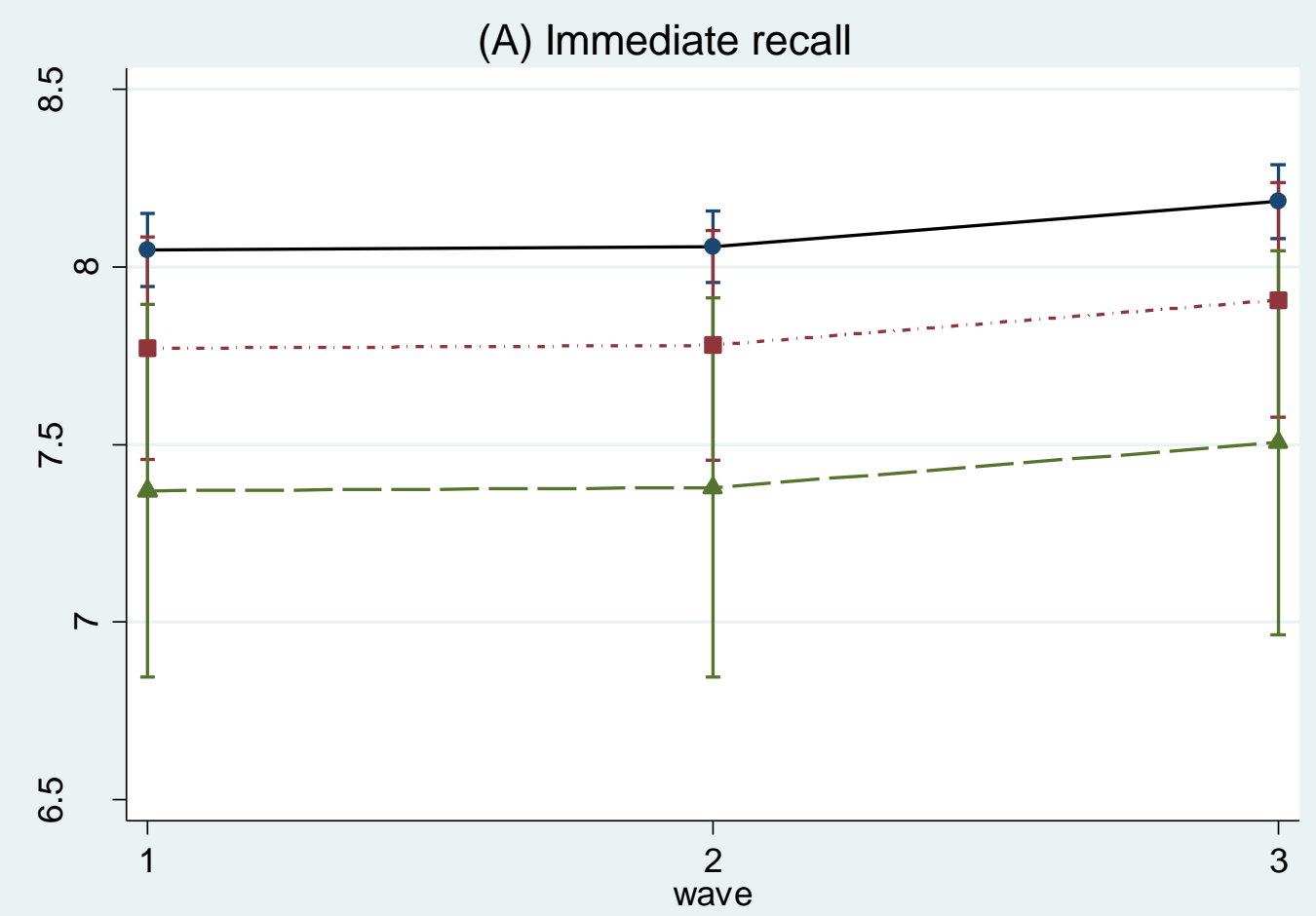

(B) Delayed recall

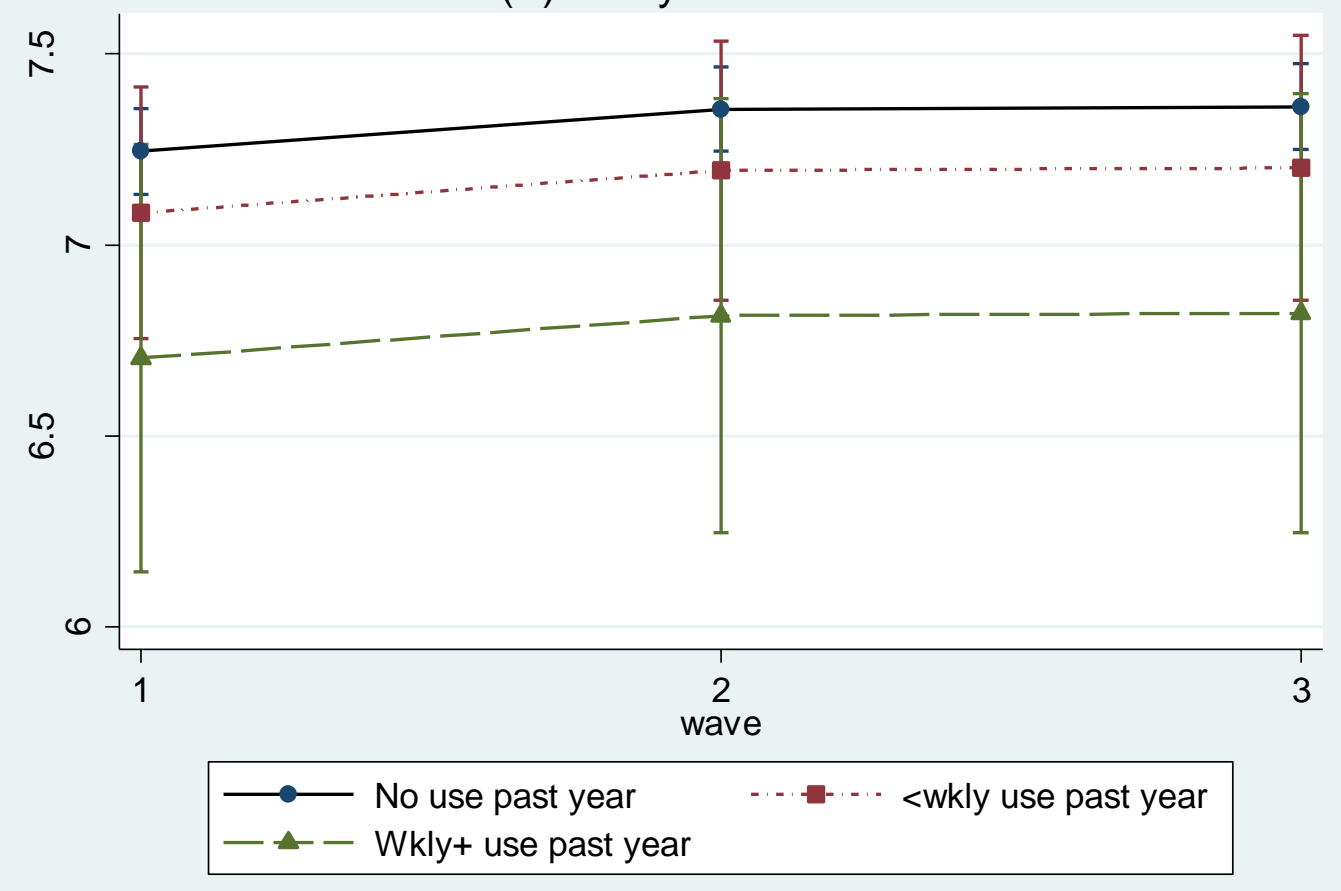

Figure 1. Predicted mean (95\% CI) immediate recall score (A) and delayed recall score (B) by wave adjusted for correlates of cannabis use and premorbid verbal ability. 